\title{
Effect of Silicon Content on the Microstructure and Mechanical Properties of Dual-Phase Steels
}

\author{
J. Drumond • O. Girina • J. F. da Silva Filho • \\ N. Fonstein · C. A. Silva de Oliveira
}

Received: 2 August 2012/Revised: 21 September 2012/Published online: 17 October 2012

(C) Springer Science+Business Media New York and ASM International 2012

\begin{abstract}
An experimental investigation was conducted using laboratory-processed, low carbon $0.08 \mathrm{C}-2.0 \mathrm{Mn}-$ $0.2 \mathrm{Cr}-0.15 \mathrm{Mo}$ steels with different $\mathrm{Si}$ contents to evaluate the influence of $\mathrm{Si}$ additions on the mechanical properties and microstructure of dual-phase steels. The heat treatment was carried out in a salt bath furnace to heat the samples between 720 and $860{ }^{\circ} \mathrm{C}$; samples were held isothermally for $60 \mathrm{~s}$, followed by air cooling or water quenching. This was accomplished by evaluating the formation of austenite at various intercritical temperatures during annealing and its decomposition during subsequent cooling. It was found that $\mathrm{Si}$ addition accelerates the recrystallization of ferrite during heating in the intercritical temperature range, which in turn promotes the formation of austenite through the nucleation process, followed by grain growth. Addition of $\mathrm{Si}$ favors the formation of a homogeneous austenite of higher hardenability resulting in a higher volume of martensite in the final structure. Thus, a silicon-bearing steel has been demonstrated to possess a higher strength in comparison with Si-free steel.
\end{abstract}

Keywords Dual-phase $\cdot$ Heat treatment $\cdot$ Microstructures · Recrystallization

J. Drumond $(\bowtie) \cdot$ J. F. da Silva Filho

ArcelorMittal Vega, São Francisco do Sul, Santa Catarina, Brazil

e-mail: juliovany.drumond@gmail.com

O. Girina $\cdot$ N. Fonstein

ArcelorMittal Global R\&D, East Chicago, IN, USA

C. A. S. de Oliveira

Universidade Federal de Santa Catarina, Florianópolis,

Santa Catarina, Brazil

\section{Introduction}

It has been shown that the addition of $\mathrm{Si}$ in high strength steels, and dual-phase steels in particular, is very effective in improving the balance of strength and ductility [1,2], presumably through critical changes in the microstructure. The mechanism through which $\mathrm{Si}$ influences the final structure and mechanical properties is not fully understood. As this final microstructure is strongly dependent on the austenite formation during annealing and its subsequent decomposition during cooling, the evaluation of the features of austenite formation affected by $\mathrm{Si}$ addition is of fundamental importance. During intercritical annealing, a complex interaction between recrystallization, grain growth, and phase transformation occurs [3, 4]. The degree of such interplay depends first of all on the chemical composition of the steel (e.g., microalloying additions) and processing parameters $[5,6]$. Therefore, the present study attempts to investigate the effect of $\mathrm{Si}$ addition on the final microstructure and mechanical properties of dual-phase steels in conjunction with the evolution of recrystallization of ferrite and austenite formations during annealing in the intercritical temperature range.

\section{Experimental Procedure}

Two laboratory heats with a carbon content of $\sim 0.085 \%$ and alloyed with two different amounts of silicon were investigated. The chemical compositions of the studied steels are shown in Table 1. Elements such as sulfur, phosphorus, copper, and nickel are present only in residual levels.

Heats of $45 \mathrm{~kg}$ of two steels studied were melted in a vacuum induction furnace. Hot rolling was conducted in two steps. The ingots, reheated at $1250{ }^{\circ} \mathrm{C}$, were hot-rolled 
Table 1 Chemical composition of investigated steels, wt.\%

\begin{tabular}{llllll}
\hline Steel & C & Mn & Cr & Mo & Si \\
\hline Si-free & 0.082 & 2.07 & 0.22 & 0.15 & 0.007 \\
Si-containing & 0.086 & 2.12 & 0.21 & 0.14 & 0.314 \\
\hline
\end{tabular}

Table 2 Calculated critical temperatures

\begin{tabular}{lll}
\hline Steel & $\mathrm{Ac}_{1}\left({ }^{\circ} \mathrm{C}\right)$ & $\mathrm{Ac}_{3}\left({ }^{\circ} \mathrm{C}\right)$ \\
\hline Si-free & 705 & 823 \\
Si-containing & 713 & 833 \\
\hline
\end{tabular}

into plates of 20-mm thickness. Plates, in turn, were reheated again at $1200{ }^{\circ} \mathrm{C}$ and processed into hot-rolled sheets of $3.0-\mathrm{mm}$ gauge with finishing rolling temperature of $880{ }^{\circ} \mathrm{C}$, followed by water cooling on the run out table to $650{ }^{\circ} \mathrm{C}$. In order to simulate the coiling process, hotrolled sheets were transferred to a furnace with a controlled inert atmosphere, held for $1 \mathrm{~h}$ at $650{ }^{\circ} \mathrm{C}$, and cooled to room temperature within the furnace at $\sim 30{ }^{\circ} \mathrm{C}$ per hour. Hot-rolled sheets were ground on both sides to ensure a decarburized-free surface, followed by cold rolling with about $60 \%$ reduction to $1.25-\mathrm{mm}$ gauge. The full hard steel was then cut into coupons for follow-up heat treatments.

The values of $\mathrm{Ac}_{1}$ and $\mathrm{Ac}_{3}$ temperatures of comparable steels were determined in accordance with Andrews' equations [7]:

$$
\begin{aligned}
\mathrm{Ac}_{1}= & 723-10.7 \mathrm{Mn}-16.9 \mathrm{Ni}+29.1 \mathrm{Si}+16.9 \mathrm{Cr} \\
& +290 \mathrm{As}+6.38 \mathrm{~W} \\
\mathrm{Ac}_{3}= & 910-203 \mathrm{C}^{1 / 2}-15.2 \mathrm{Ni}+44.7 \mathrm{Si}+104 \mathrm{~V} \\
& +31.5 \mathrm{Mo}+13.1 \mathrm{~W}-30 \mathrm{Mn}-11 \mathrm{Cr}-20 \mathrm{Cu} \\
& +700 \mathrm{P}+400 \mathrm{Al}+120 \mathrm{As}+400 \mathrm{Ti}
\end{aligned}
$$

Table 2 displays the calculated temperatures, $\mathrm{Ac}_{1}$ and $\mathrm{Ac}_{3}$, for the steels under investigation. As expected, an addition of $0.3 \%$ of silicon slightly increases both temperatures.

Heat treatment was carried out utilizing a salt bath furnace containing barium chloride $\left(\mathrm{BaCl}_{2}\right)$, heated by natural gas. The heating temperature was varied by design between 720 and $860{ }^{\circ} \mathrm{C}$, with incremental steps of $20^{\circ} \mathrm{C}$, as presented in Fig. 1. The samples were isothermally held for $60 \mathrm{~s}$ followed by either air cooling or water quenching to room temperature.

In order to prevent a location dependent temperature gradient in the samples, a concentric rounded device was designed and prepared using a stainless steel ring of 200-mm diameter. This device helped in positioning each of the compared samples on the same iso-temperature line at the same distance from the container wall (Fig. 2).

As mentioned above, two cooling treatments were applied in accordance with different tasks outlined in the current investigation:

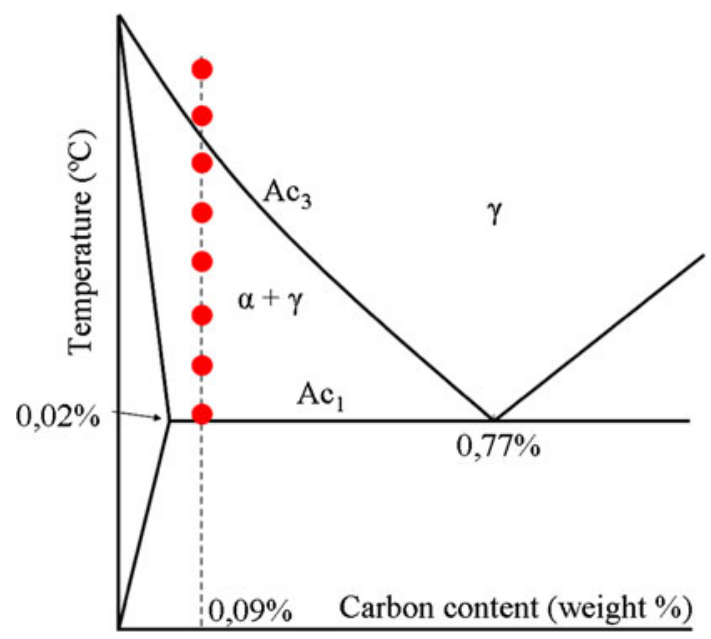

Fig. 1 Equilibrium $\mathrm{Fe}-\mathrm{C}$ diagram with the dots illustrating the preselected heating temperatures for annealing

- Water quenching results in the full transformation of the formed austenite to martensite without any change in the amount or morphology of ferrite. This facilitates the investigation of the kinetics of austenite formation and the evaluation of the recrystallization of ferrite using microstructural observation.

- Air cooling provides the opportunity to evaluate the effect of Si on the hardenability of austenite and can be judged based on the ratio of ferrite/bainite/martensite microstructure constituents.

Tensile tests of annealed samples, cut in the L-direction, were performed in accordance with DIN-EN 10002. Ultimate tensile strength (UTS), yield strength (YS), and total elongation (TE) were evaluated.

Investigation of microstructures and phase quantification were conducted using both light microscopy and scanning electron microscopy. Each sample was etched using 2\% Nital and/or 4\% Picral for microstructural investigation. Volume fractions of carbon-containing phases such as bainite and martensite were calculated manually using a mesh device containing 920 small squares. Three fields were analyzed for each sample.

\section{Results and Discussion}

Silicon Effect on Recrystallization and Austenitization

The starting microstructures of the as-received cold-rolled steels are shown in Fig. 3. The light and dark areas in the micrograph are elongated grains of ferrite and either deformed colonies of pearlite and/or martensite/austenite constituents, respectively.

The recrystallization of ferrite and the austenitization process were studied by microstructural analysis of cold-rolled 

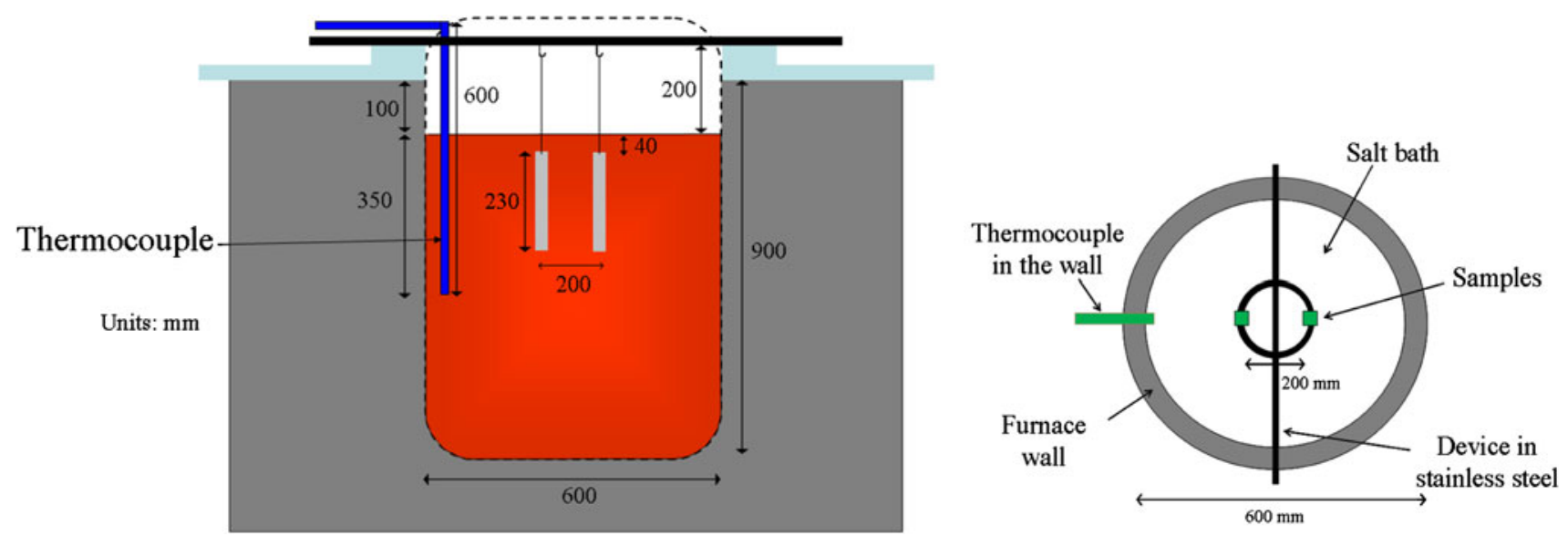

Fig. 2 Salt bath furnace and specimen holder configuration for heat treating with view from the top
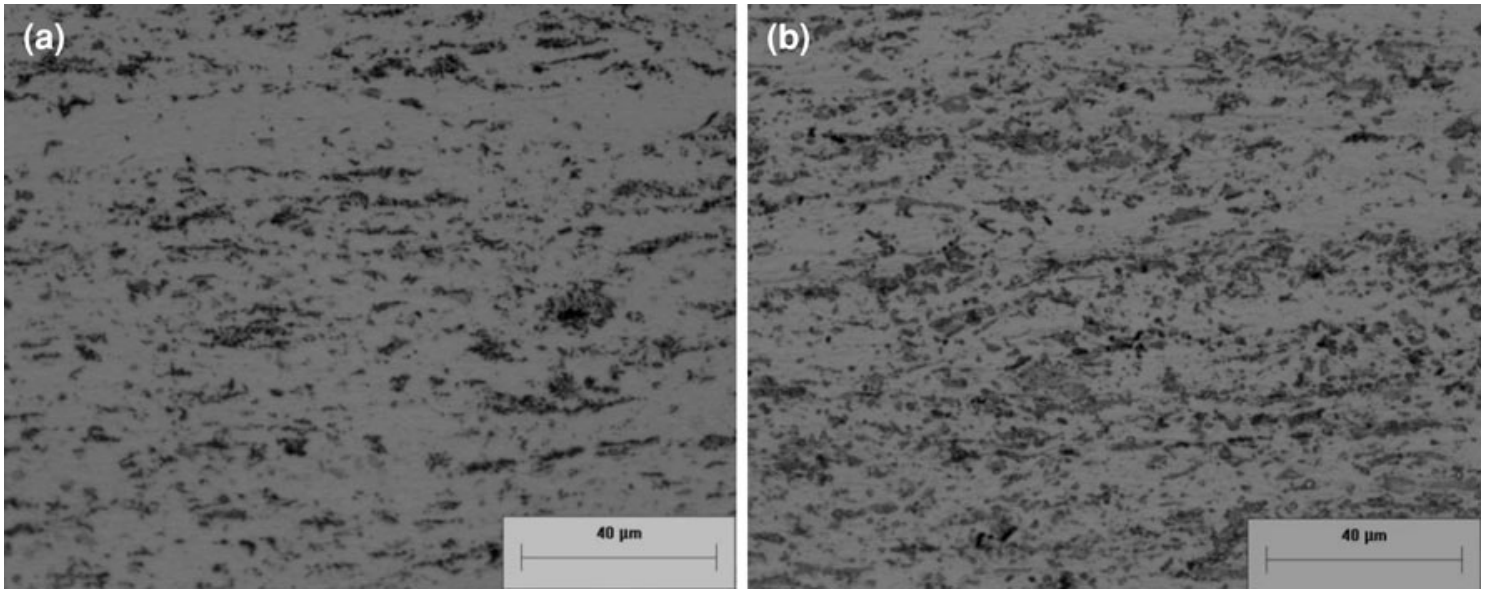

Fig. 3 Light micrographs after cold rolling, Nital, and Picral etchant: (a) Si-free steel and (b) Si-containing steel

samples that had been annealed at preselected temperatures, followed by water quenching. A representative set of microstructures from samples annealed between 720 and $760{ }^{\circ} \mathrm{C}$ is presented in Fig. 4 containing arrows that represent nonrecrystallized ferrite grains.

It was observed that $\mathrm{Si}$ addition accelerates the recrystallization of ferrite. As seen from the microstructures presented in Fig. 4, the ferrite recrystallization in the Si-containing steel is mostly completed at $760{ }^{\circ} \mathrm{C}$, while the Si-free steel is only partially recrystallized at the same temperature. The accelerated recrystallization of ferrite in the Si-containing steel can be related to the effect of the initial structure [8,9]. It was observed that the Si-containing steel exhibits a more refined cold-rolled structure with a higher volume of carbon-containing phases. It is well known that smaller grains have a larger outline area and thus greater surface energy. Therefore, the higher surface energy associated with the grain boundaries of the Si-containing steel will generate a higher thermodynamic potential for ferrite recrystallization.

Another characteristic of the process can be better evidenced in Fig. 5, which presents in detail the microstructure of sample of Si-free steel annealed at $760{ }^{\circ} \mathrm{C}$, followed by water quenching. As observed, the recrystallization of ferrite and the formation of austenite proceed simultaneously during heating in the intercritical annealing.

The difference in the extent of recrystallization affects the process of austenitization. Austenite formation in the Si-free steel takes place in the structure containing a partially recrystallized ferrite, while in the Si-containing steel, the austenite starts to form when the recrystallization of ferrite is mostly completed.

As previously reported $[10,11]$, the austenite nuclei form first at the ferrite-cementite interfaces in the 

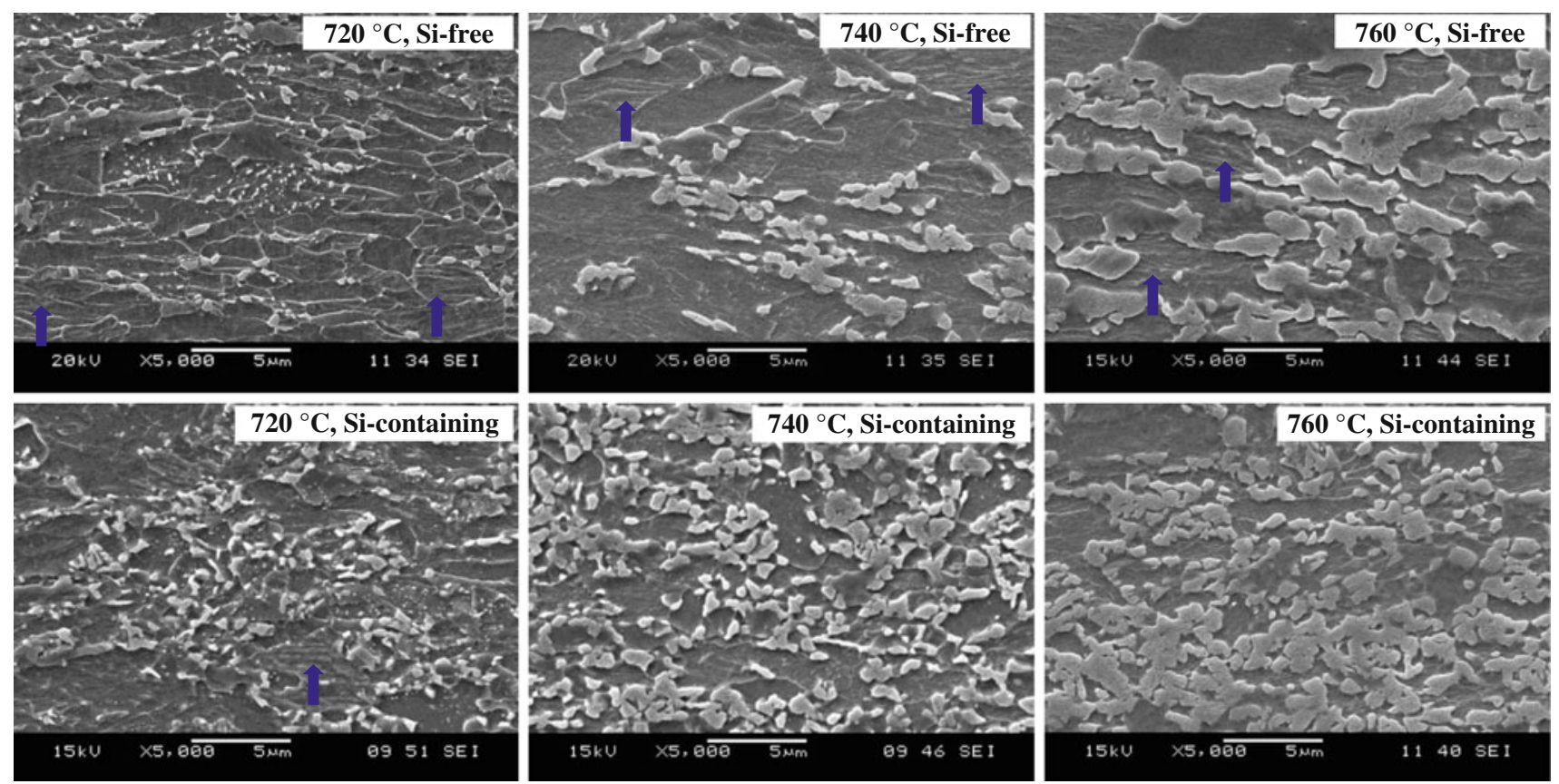

Fig. 4 Microstructures of Si-free and Si-containing steels, after annealing between 720 and $760{ }^{\circ} \mathrm{C}$ followed by water quenching. SEM, $2 \%$ Nital

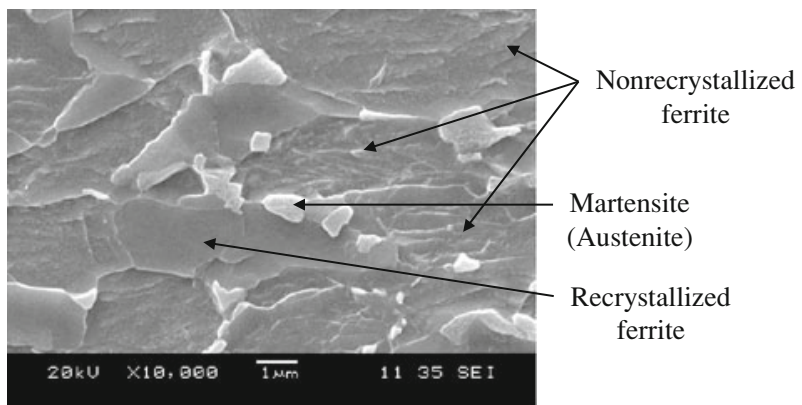

Fig. 5 Microstructure of Si-free steel after annealing at $760{ }^{\circ} \mathrm{C}$ followed by water quenching. SEM, $2 \%$ Nital

carbon-containing colonies, such as pearlite/bainite or martensite, and later at the recrystallized ferrite grain boundaries. The simultaneous occurrence of two processes, recrystallization of ferrite and formation of austenite nuclei, has a significant effect on the kinetics of austenite formation. The austenite formation occurs through the nucleation and growth processes controlled by the diffusion of carbon. In the Si-free steel, the presence of a large volume of nonrecrystallized ferrite grains leads to a small volume of austenite nuclei followed by growth of this austenite along the rolling direction (region where the carbon-rich areas are located), because of the preferred diffusion of carbon in those regions. Therefore, the formation of a smaller amount of coarse elongated islands of austenite becomes preferable

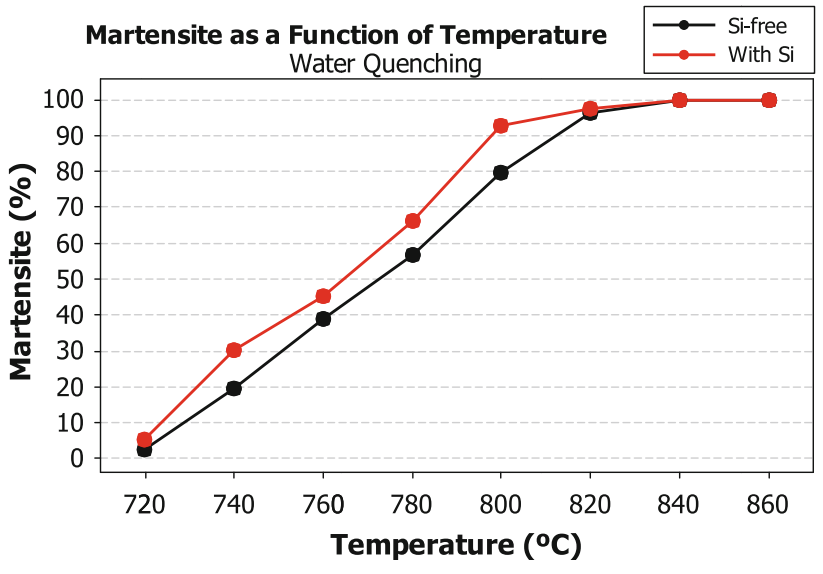

Fig. 6 Effect of $\mathrm{Si}$ on the volume of martensite after water quenching, as a function of annealing temperature

in the Si-free steel. In contrast, in the Si-containing steel, the recrystallization process starts earlier and when the austenite formation begins, most ferrite grains are already recrystallized. This facilitates the formation of multiple austenite nuclei, and the formation of austenite is mostly occurring through the nucleation process which results in a more uniform distribution of smaller islands of martensite within the matrix of refined grains of ferrite.

This explanation is confirmed by the microstructures shown in Fig. 4, especially at $760{ }^{\circ} \mathrm{C}$. The fine martensite islands obtained in the Si-containing steel are more evenly distributed in comparison to those formed in the Si-free 
steel, where the coarse martensite islands are aligned along the rolling direction.

As shown in Fig. 6, the growth of austenite through the increased density of austenite nuclei in the Si-steel results in a higher volume fraction of austenite in the intercritical temperature range. This is facilitated by an earlier completion of recrystallization and higher carbon diffusion along the refined grain boundaries of ferrite.

As seen in Fig. 6, the volume of martensite, which represents the volume of austenite before quenching, increases with the increasing annealing temperature. The



Fig. 7 Effect of silicon on the volume of martensite, as a function of annealing temperature, after air cooling
Si-containing steel exhibits $\sim 10 \%$ higher volume of martensite at the same annealing temperature than the $\mathrm{Si}$-free steel. At temperatures close to the full austenitization $\left(\sim 820^{\circ} \mathrm{C}\right)$, the effect of $\mathrm{Si}$ addition on the volume of formed austenite is insignificant due to the large amount of austenite, which makes the diffusion distance for carbon to become much shorter.

\section{Silicon Effect on Structure and Mechanical Properties}

The effect of silicon addition on the structure and final mechanical properties was analyzed through the samples cooled by air. As illustrated in Fig. 7, the Si-containing steel shows a larger volume fraction of martensite at all annealing temperatures than the $\mathrm{Si}$-free steel, which is related to the previous process of austenitization.

In general, the increasing volume of austenite means reduced the hardenability of the austenite because of the lower average carbon content. However, it is necessary to take into account the morphology and homogeneity of the formed austenite. As mentioned earlier, the formation of austenite in the Si-containing steel takes place through the nucleation process followed by limited growth, resulting in a refined microstructure with small islands of austenite with uniform carbon distribution. In the case of the Si-free steel, the growth of austenite occurs through austenite nuclei growth in the ferrite, resulting in the formation of coarse islands of nonhomogeneous austenite. During slow cooling, the portions of austenite with a lower carbon
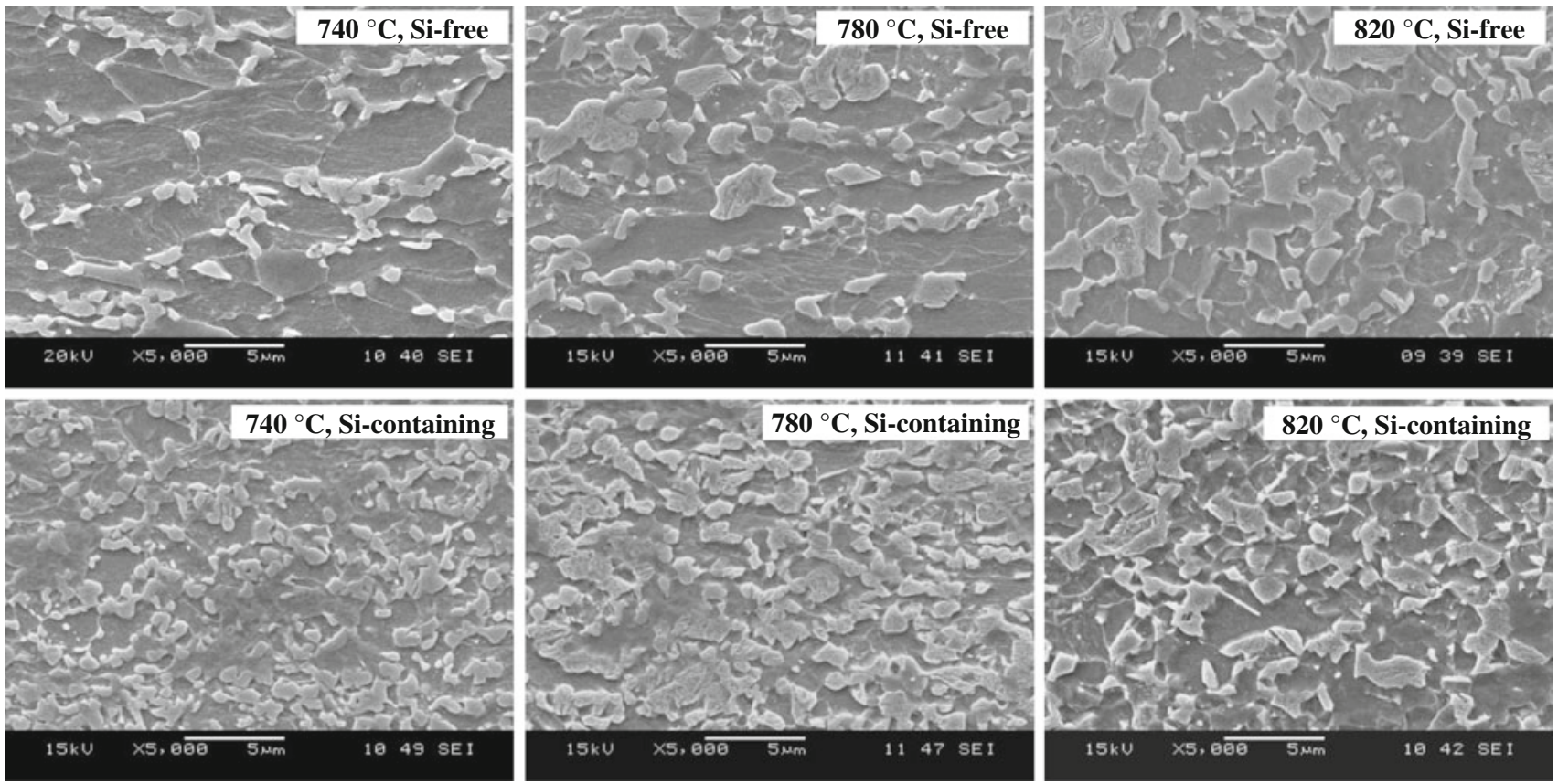

Fig. 8 Microstructures of Si-free and Si-containing steels, after annealing between 740 and $820{ }^{\circ} \mathrm{C}$ followed by air cooling. SEM, $2 \%$ Nital 
content transform to ferrite and/or bainite instead of martensite.

The difference in the homogeneity of the martensite in both steels may be observed in Fig. 8, showing a

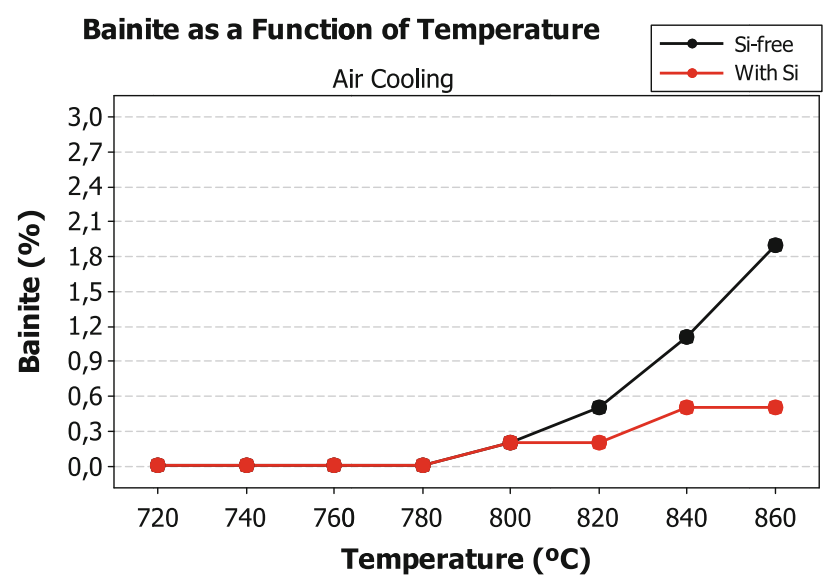

Fig. 9 Effect of $\mathrm{Si}$ on the volume of bainite, as a function of annealing temperature, after air cooling

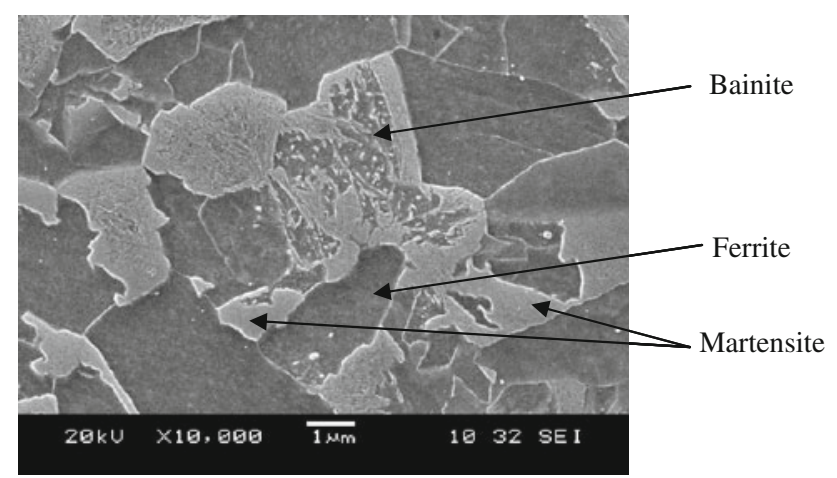

Fig. 10 Microstructure of Si-free steel after annealing at $860{ }^{\circ} \mathrm{C}$ followed by air cooling. SEM, $2 \%$ Nital

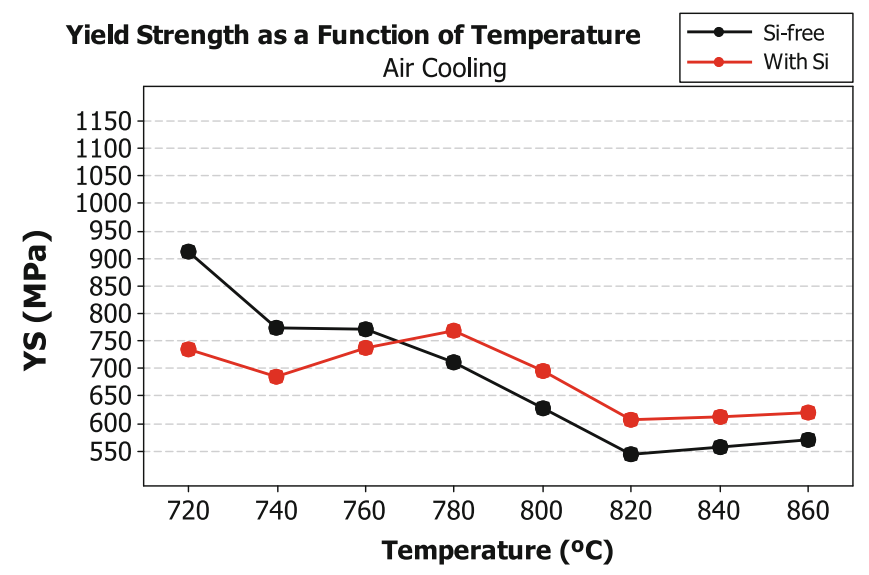

representative set of microstructures for samples annealed between 740 and $820{ }^{\circ} \mathrm{C}$, followed by air cooling.

As shown in Fig. 9, the Si-free steel exhibits a higher volume of bainite in comparison with the Si-containing steel, during slow cooling from temperatures above $800{ }^{\circ} \mathrm{C}$. As explained earlier, the nonhomogeneous austenite of lower hardenability in the Si-free steel induces the formation of a larger fraction of bainite instead of martensite.

Figure 10 presents in detail the microstructure of Si-free steel annealed at $860{ }^{\circ} \mathrm{C}$ followed by air cooling; bainite in addition to ferrite and martensite is observed.

As shown in Fig. 11, the YS in the Si-free steel is initially higher than that in the Si-containing steel because of the presence of nonrecrystallized ferrite grains. The initial relative difference in strength between the two alloys is approximately $200 \mathrm{MPa}$ at $720^{\circ} \mathrm{C}$; this difference decreases until a temperature of $760{ }^{\circ} \mathrm{C}$, at which most of the ferrite is already recrystallized. The UTS increases with increasing annealing temperature up to $760{ }^{\circ} \mathrm{C}$ for both steels. The same level of UTS in both steels at temperatures below $760{ }^{\circ} \mathrm{C}$, regardless of a higher volume of martensite in the Si-containing steel, is also attributable to the enhanced contribution of a higher volume of nonrecrystallized ferrite grains in the $\mathrm{Si}$-free steel. At annealing temperatures above $760{ }^{\circ} \mathrm{C}$, the $\mathrm{Si}$ addition promotes a higher level of UTS and YS due to a higher volume of martensite, as shown in Fig. 7.

The higher level of UTS in the Si-containing steel is observed even after annealing above the $\mathrm{Ac}_{3}$ temperature when $100 \%$ of austenite is present in both steels. This difference can be partially attributed to the Si strengthening of ferrite that could contribute $\sim 30 \mathrm{MPa}$ to UTS [12]. Furthermore, the explanation may reside in potential differences in microstructural constituents and their properties. As is well known, the final microstructure after

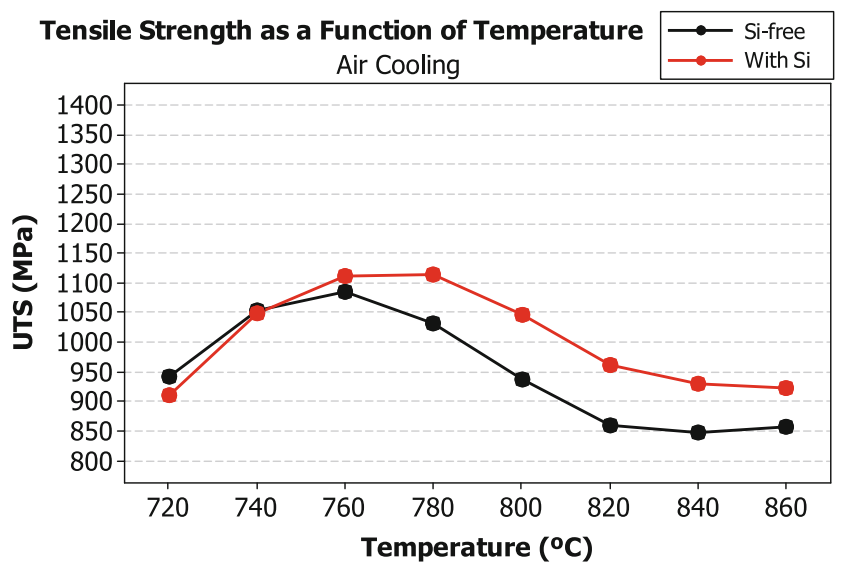

Fig. 11 Effect of Si addition on the mechanical properties of the steel, for different annealing temperatures 
cooling reflects not only the type and amount of austenite formed during heating and isothermal holding, but also the hardenability of austenite, which strongly depends on both carbon content and the homogeneity of its composition.

\section{Conclusions}

1. Addition of Si accelerates the recrystallization of ferrite during heating in the intercritical temperature range, and the same can be attributed to the effect of a more refined initial cold-rolled structure in the Si-containing steel.

2. While the recrystallization and austenitization processes are proceeding simultaneously in the Si-free steel, the Si-containing steel shows that ferrite recrystallization occurs earlier, and thus the austenite formation occurs preferably through the nucleation process, which leads to a uniform distribution of small islands of martensite within the refined ferrite matrix.

3. Si addition increases the strength of dual-phase steels after annealing and slow cooling because of the formation of a high volume of homogeneous austenite of high hardenability, leading to a high volume of martensite in the final structure.

Acknowledgments The authors thank ArcelorMittal for the permission to publish this article, and the Sociesc (Sociedade Educacional do Estado de Santa Catarina) for heat-treatment contribution.

\section{References}

1. R.G. Davies, Influence of silicon and phosphorous on the mechanical properties of both ferrite and dual-phase steels. Metall. Mater. Trans. A 10, 113-118 (1979)

2. S. Hironaka, H. Tanaka, T. Matsumoto, Effect of $\mathrm{Si}$ on mechanical property of galvannealed dual phase steel. Mater. Sci. Forum 638-642, 3260-3265 (2010)

3. R.D. Doherty, D.A. Hughes, F.J. Humphreys, J.J. Jonas, Current issues in recrystallization: a review. Mater. Sci. Eng. A A238, 219-274 (1997)

4. T. Ogawa, N. Maruyama, N. Sugiura, N. Yoshinaga, Incomplete recrystallization and subsequent microstructural evolution during intercritical annealing in cold-rolled low carbon steels. ISIJ Int. 50(3), 469-475 (2010)

5. J. Huang, W.J. Poole, M. Militzer, Austenite formation during intercritical annealing. Metall. Mater. Trans. A 35, 3363-3375 (2004)

6. M.M. Souza, J.R.C. Guimarães, K.K. Chawla, Intercritical austenitization of two $\mathrm{Fe}-\mathrm{Mn}-\mathrm{C}$ steels. Metall. Mater. Trans. A 13, 575-579 (1982)

7. K.W. Andrews, Empirical formulae for the calculation of some transformation temperatures. ISIJ Int. 203, 721-727 (1965)

8. F.G. Caballero, C. Capdevila, C. García De Andrés, Modelling of kinetics of austenite formation in steels with different initial microstructures. ISIJ Int. 41(10), 1093-1102 (2001)

9. R.R. Mohanty, O.A. Girina, N.M. Fonstein, Effect of heating rate on the austenite formation in low-carbon high-strength steels annealed in the intercritical region. Metall. Mater. Trans. A 42, 3680-3690 (2011)

10. J. Wu, P.J. Wray, M. Hua, C.I. Garcia, A.J. DeArdo, Austenite formation and decomposition. Mater. Sci. Technol. 19, 291-309 (2003)

11. G.R. Speich, V.A. Demarest, R.L. Miller, Formation of austenite during intercritical annealing of dual-phase steels. Metall. Mater. Trans. A 12, 1419-1428 (1981)

12. F.B. Pickering, Microalloying 75 (USS, New York, 1977), pp. $9-30$ 